\title{
Cortical phase changes measured using 7-T MRI in subjects with subjective cognitive impairment, and their association with cognitive function
}

Sanneke van Rooden ${ }^{\mathrm{a}, \mathrm{b}_{*}{ }^{\dagger}}$, Mathijs Buijs $\mathrm{a}^{\mathrm{a}, \mathrm{b}}{ }^{\mathrm{b}}$, Marjolein E. van Vliet $^{\mathrm{a}, \mathrm{b}}$, Maarten J. Versluis ${ }^{\mathrm{a}, \mathrm{b}}$, Andrew G. Webb ${ }^{\mathrm{a}, \mathrm{b}}$, Ania M. Oleksik ${ }^{\mathrm{c}}$, Lotte van de Wiel ${ }^{\mathrm{d}}$, Huub A. M. Middelkoop ${ }^{d}$, Gerard Jan Blauw c,e, Annelies W. E. Weverling-Rynsburger ${ }^{\prime}$, Jeroen D. C. Goos ${ }^{\mathrm{g}}$, Wiesje M. van der Flier ${ }^{\text {g, }}$, Ted Koene ${ }^{\mathrm{g}}$, Philip Scheltens ${ }^{\mathrm{g}}$, Frederik Barkhofi, Ondine van de Rest ${ }^{j}$, P. Eline Slagboom ${ }^{k}$, Mark A. van Buchem ${ }^{a, b}$ and Jeroen van der Grond ${ }^{a, b}$

\begin{abstract}
Studies have suggested that, in subjects with subjective cognitive impairment (SCI), Alzheimer's disease (AD)-like changes may occur in the brain. Recently, an in vivo study has indicated the potential of ultra-high-field MRI to visualize amyloidbeta $(A \beta)$-associated changes in the cortex in patients with AD, manifested by a phase shift on $T_{2}{ }^{*}$-weighted MRI scans. The main aim of this study was to investigate whether cortical phase shifts on $T_{2}{ }^{*}$-weighted images at 7T in subjects with $\mathrm{SCl}$ can be detected, possibly implicating the deposition of $\mathrm{A} \beta$ plaques and associated iron. Cognitive tests and $T_{2}{ }^{*}$-weighted scans using a 7-T MRI system were performed in 28 patients with AD, 18 subjects with SCI and 27 healthy controls (HCs). Cortical phase shifts were measured. Univariate general linear modeling and linear regression analysis were used to assess the association between diagnosis and cortical phase shift, and between cortical phase shift and the different neuropsychological tests, adjusted for age and gender. The phase shift (mean, 1.19; range, 1.00-1.35) of the entire cortex in $\mathrm{AD}$ was higher than in both $\mathrm{SCl}$ (mean, 0.85; range, 0.73-0.99; $p<0.001$ ) and HC (mean, 0.94; range, 0.79-1.10; $p<0.001$ ). No AD-like changes, e.g. increased cortical phase shifts, were found in subjects with $\mathrm{SCl}$ compared with $\mathrm{HCs}$. In SCl, a significant association was found between memory function (Wechsler Memory Scale, WMS) and cortical phase shift ( $\beta=-0.544$, $p=0.007$ ). The major finding of this study is that, in subjects with $\mathrm{SCl}$, an increased cortical phase shift measured at high field is associated with a poorer memory performance, although, as a group, subjects with $\mathrm{SCl}$ do not show an increased phase shift compared with HCs. This increased cortical phase shift related to memory performance may contribute to the understanding of $\mathrm{SCl}$ as it is still unclear whether SCI is a sign of pre-clinical AD. Copyright $\odot 2014$ John Wiley \& Sons, Ltd.
\end{abstract}

Keywords: subjective cognitive impairment; Alzheimer's disease; brain imaging; phase; human 7-T MRl; AD pathology; cognition

* Correspondence to: S. van Rooden, Department of Radiology, C3-Q, Leiden University Medical Center, PO Box 9600, 2300 RC Leiden, the Netherlands. E-mail: S.van_Rooden@lumc.nl

a S. van Rooden, M. Buijs, M. E. van Vliet, M. J. Versluis, A. G. Webb, M. A. van Buncem, J. van der Grond

C. J. Gorter Center for High-Field MRI, Leiden University Medical Center, Leiden, the Netherlands

b S. van Rooden, M. Buijs, M. E. van Vliet, M. J. Versluis, A. G. Webb, M. A. van Buncem, J. van der Grond

Department of Radiology, Leiden University Medical Center, Leiden, the Netherlands

c A. M. Oleksik, G. J. Blauw

Department of Gerontology and Geriatrics, Leiden University Medical Center, Leiden, the Netherlands

d L. van de Wiel, H. A. M. Middelkoop

Department of Neuropsychology, Leiden University Medical Center, Leiden, the Netherlands

e G. J. Blauw

Department of Gerontology and Geriatrics, Bronovo Hospital, Den Haag, the Netherlands

f A. W. E. Weverling-Rynsburger

Department of Gerontology and Geriatrics, Diaconessen Hospital, Leiden, the Netherlands

g J. D. C. Goos, W. M. van der Flier, T. Koene, P. Scheltens

Alzheimer Center and Department of Neurology, Neuroscience Campus Amsterdam, VU University Medical Center, Amsterdam, the Netherlands h W. M. van der Flier

Department of Epidemiology and Biostatistics, VU University Medical Center, Amsterdam, the Netherlands

i F. Barkhof

Department of Radiology, VU University Medical Center, Amsterdam, the Netherlands

j O. van de Rest

Division of Human Nutrition, Wageningen University, Wageningen, the Netherlands

k P. E. Slagboom

Department of Molecular Epidemiology, Leiden University Medical Center, Leiden, the Netherlands

These authors contributed equally to this work.

Abbreviations used: $A \beta$, amyloid-beta; $A D$, Alzheimer's disease; ANOVA, analysis of variance; CAMCOG, Cambridge Cognitive Examination; CSF, cerebrospinal fluid; GDS, Geriatric Depression Scale; GM, gray matter; $H C$, healthy control; $\mathrm{MCl}$, mild cognitive impairment; MMSE, Mini Mental State Examination; NFT, neurofibrillary tangle; NINCDS-ADRDA, National Institute of Neurological and Communicative Disorders and Stroke-Alzheimer's Disease and Related Disorders Association; PET, positron emission tomography; ROI, region of interest; $S C l$, subjective cognitive impairment; SD, standard deviation; TMT, Trail Making Test; WM, white matter; WMS, Wechsler Memory Scale. 


\section{INTRODUCTION}

Subjective cognitive impairment ( $\mathrm{SCl}$ ) is common in the elderly and refers to a subjective decline in levels of cognitive functioning, which cannot be confirmed by neuropsychological evaluation (1). Longitudinal population-based studies have reported an association with future cognitive decline (2) and dementia (3). Moreover, neuroimaging studies have shown that, in subjects with $\mathrm{SCl}$, Alzheimer's disease (AD)-like changes, such as loss of volume in the medial temporal lobe and hippocampus, may have already occurred before cognitive decline becomes evident (4-9). This suggests that the elderly with $\mathrm{SCl}$ may be at risk for the development of AD. Alternatively, cognitive complaints may be caused by other factors, such as depression, anxiety and quality of life (10-13).

Recently, it has been demonstrated that $T_{2}{ }^{*}$-weighted MRI at high field provides indirect evidence of the presence of $A D$ pathology $(14,15)$. This approach is based on the finding that, in autopsy material of patients with $A D$, amyloid-beta $(A \beta)$ deposition and neurofibrillary tangles (NFTs), as well as tau deficiency, are found to co-localize with cortical iron accumulation (16-19). Based on the high sensitivity of $T_{2}{ }^{*}$-weighted MRI at $7 \mathrm{~T}$ in detecting small cerebral iron deposits $(20,21)$, we have shown in a previous study that, in patients with $A D$, the magnitude of the observed cortical phase shift in $T_{2}{ }^{*}$-weighted phase images is correlated with global cognitive functioning, and demonstrates a high sensitivity in differentiating patients with $A D$ from controls (14). Based on the fact that $A \beta$ plaques and NFTs occur up to 10-20 years before cognitive decline can be measured (22), and the findings that $\mathrm{SCl}$ predicts the future diagnosis of $\mathrm{AD}$ $(23,24)$, it could be hypothesized that, in subjects with SCl, differences in $T_{2}{ }^{*}$-weighted cortical phase shifts may already be present before cognitive decline can be determined.

The main aim of this study was to investigate whether cortical phase shifts on $T_{2}{ }^{*}$-weighted images at $7 \mathrm{~T}$ in subjects with $\mathrm{SCl}$ can be detected, suggesting the deposition of $A \beta$ plaques and associated iron. The secondary aim was to investigate which cognitive domains are associated with cortical phase shifts in these subjects.

\section{MATERIALS AND METHODS}

\section{Participants}

This study was approved by the local institutional review board. In all cases, informed consent was obtained according to the Declaration of Helsinki (25). In total, 28 patients with AD, with a mean age of 71.2 years (range, 54-86 years; 18 men and 10 women), 18 subjects with $\mathrm{SCl}$, with a mean age of 66.5 years (range, 49-85 years; 13 men and five women), and 27 healthy controls ( $\mathrm{HCs}$ ), with a mean age of 68.9 years (range, $52-80$ years; 16 men and 11 women), were included.

Patients with $A D$ and subjects with $\mathrm{SCl}$ were recruited from the memory clinic of the Leiden University Medical Center, the VU University Medical Center in Amsterdam, the Bronovo Hospital in The Hague and the Diaconessen Hospital in Leiden. Memory clinic patients were referred to the hospital by their general practitioner or a medical specialist. Prior to the 7-T study, all patients underwent a routine clinical protocol, comprising a whole-brain clinical MRI and a battery of neuropsychological tests measuring global cognitive functioning [Mini Mental State Examination (MMSE) (26) and Cambridge Cognitive Examination (CAMCOG) (27)], memory [Wechsler Memory Scale (WMS) (28) including digit span forward and backward (working memory)], executive function [Trail Making Test (TMT) part B (cognitive flexibility) (29) and STROOP card 3 (inhibition) (30)], psychomotor speed [TMT part A) (29)] and depression [abbreviated Geriatric Depression Scale (GDS) (31)]. A general medical and neurological examination was performed by a neurologist, psychiatrist or internist-geriatrician. Diagnosis was made in a multidisciplinary consensus meeting using the National Institute of Neurological and Communicative Disorders and Stroke-Alzheimer's Disease and Related Disorders Association (NINCDS-ADRDA) criteria for the diagnosis of probable $A D$ (32). SCl was defined by the subjective feeling of memory decline for which these subjects (based on memory complaints) were referred to the memory clinic; however, subjects with $\mathrm{SCl}$ performed within the normal range on standard neuropsychological tests [i.e. criteria for mild cognitive impairment $(\mathrm{MCl})$, dementia or other neurologic or psychiatric disorder were not fulfilled]. Participants with the diagnosis ' $\mathrm{SCl}$ ' and 'probable $\mathrm{AD}^{\prime}$ ', who were capable of giving informed consent (MMSE $\geq 19$ ), were selected for inclusion. Patients with $A D$ and subjects with $\mathrm{SCl}$ were selected for inclusion in the 7-T study either retrospectively within 1 year after attending the memory clinic, or otherwise prospectively.

HCs were recruited as part of the Leiden Longevity Study, the details of which have been described elsewhere (33). So as not to predispose for familial longevity, only partners of offspring were included. Subjects were included if they lived independently, were aged $\leq 85$ years, had a body mass index between 23 and $35 \mathrm{~kg} / \mathrm{m}^{2}$, an MMSE $\geq 25$ and a GDS $\leq 4$. Individuals who were engaged in heavy/intense physical activity, had been immobile for longer than 1 week in the preceding 3 months, had shown psychiatric or behavioral problems, or had used either thyroid medication or immunosuppressants were excluded. Subjects were screened for cognitive deficits by an internist-geriatrician, and subjects with the following diseases were excluded: hemorrhagic and ischemic stroke, Parkinson's disease, dementia, MCl, diabetes type I or II, rheumatoid arthritis, polymyalgia rheumatica, cancer, heart failure and chronic obstructive pulmonary disease. Prior to the MRI scan, all subjects underwent cognitive testing, measuring global cognitive functioning (MMSE), working memory (digit span forward and backward), executive function [TMT part B (cognitive flexibility) and STROOP card 3 (inhibition)] and psychomotor speed (TMT part A).

\section{MRI}

Image acquisition

MRI was performed on a whole-body, human, 7-T MRI system (Philips Healthcare, Best, the Netherlands) using a quadrature transmit and 16-channel receive head coil. Participants were scanned using a two-dimensional, flow-compensated, transverse, $T_{2}{ }^{*}$-weighted gradient echo scan, including the frontal and parietal regions, which are most prone to $A \beta$ deposition, with a total imaging duration of $10 \mathrm{~min}$. Positioning of this stack of slices was planned within the frontal and parietal region above the occipital lobe, using the sagittal plane of the survey scan as a reference. The middle of the stack of slices was positioned through the corpus callosum, just above the thalamus. Imaging parameters were as follows: $T R / T E=1764 / 25 \mathrm{~ms}$; flip angle, $45^{\circ}$; slice thickness, $1.0 \mathrm{~mm}$ with a $0.1-\mathrm{mm}$ interslice gap; 20 slices; field of view, $240 \times 180 \times 22 \mathrm{~mm}^{3}$; matrix size, $1024 \times 768$; in-plane spatial resolution, $0.24 \times 0.24 \mathrm{~mm}^{2}$. The bandwidth per pixel was $46 \mathrm{~Hz}$, corresponding to a readout length of approximately $22 \mathrm{~ms}$. The frequency- and phase-encoding directions were along the anterior-posterior and right-left axes, respectively. Shimming up 
to third order was performed using an image-based shimming approach (34). The phase images were subsequently unwrapped by high-pass filtering with a $92 \times 92$ kernel (35).

\section{Image analysis}

Phase values in the cortex were determined using the transverse two-dimensional $T_{2}{ }^{*}$-weighted gradient echo scans. The phase values of the cortical gray matter (GM) were determined on the unwrapped phase images in regions of interest (ROIs) in four different areas of the brain: frontal, parietal, left temporoparietal and right temporoparietal. Because of the laminar variation in the cortical areas (36), histograms perpendicular to the cortex within these regions were created to measure peak GM phase values, over at least 10 cortical regions per slice and per region. To correct for local macroscopic magnetic field inhomogeneities, subcortical white matter (WM) phase values were measured and used as an internal reference value. ROls were selected containing only the GM or WM, avoiding blood vessels, cerebrospinal fluid (CSF), WM hyperintensities and other abnormalities which could influence the results. Phase values for GM and WM were measured in these four areas per MRI slice for every other slice (10 in total), resulting in 40 phase values for GM and WM separately per subject. The phase values of the different ROIs of the four regions were averaged. Per subject, the overall phase shift between cortical GM and subcortical WM (lobar cortical phase shift) was calculated for each region and expressed in radians. All phase values reported in our article represent these averages (14).

\section{Statistics}

Where appropriate, the data are expressed as the mean \pm standard deviation. One-way analysis of variance (ANOVA) was used to assess differences in age, phase shift measurements and neuropsychological tests between patients with $A D$, subjects with $\mathrm{SCl}$ and $\mathrm{HCs}$. Post-hoc independent-samples t-tests were used to assess differences in age, phase measurements and different neuropsychological test results between groups (twosample comparison of means, two-sided test, equal variances were assumed). To evaluate differences in gender and education, chi-squared tests were performed. Univariate general linear modeling analysis was used to assess the association between diagnosis and cortical phase shifts, adjusted for age and gender. To determine the association between the different neuropsychological tests and phase shift in the cortex, linear regression analysis was used, correcting for age and gender in subjects with $\mathrm{SCl}$. All statistical analyses were performed with the Statistical Package of Social Sciences (SPSS, version 20.0; SPSS, Chicago, IL, USA).

\section{RESULTS}

The characteristics of the participants, including the mean scores for different neuropsychological tests per group, are shown in Table 1. No differences in age, gender or education were found between the groups. A small difference in performance on the digit span backwards test $(p=0.024)$ and TMT part $\mathrm{A}(p=$ 0.042 ) between subjects with $\mathrm{SCl}$ and $\mathrm{HCs}$ was found. For the other tests, no differences between these groups were found. Patients with $\mathrm{AD}$ demonstrated an overall lower cognitive performance than subjects with $\mathrm{SCl}$ and $\mathrm{HCs}$.

Figure 1 shows representative magnitude and phase images from a patient with $\mathrm{AD}$, a subject with $\mathrm{SCl}$ and an $\mathrm{HC}$. The mean phase shift of the entire cortex in patients with AD (mean, 1.19; range, 1.00-1.35) was higher than that for subjects with $\mathrm{SCl}$ (mean, 0.85; range, 0.73-0.99; adjusted for age and gender, $p<$ 0.001 ) and HCs (mean, 0.94; range, 0.79-1.10; adjusted for age

Table 1. Mean baseline characteristics, mean scores with standard deviation (SD) and range of different neuropsychological tests of healthy controls $(\mathrm{HC})$, subjects with subjective cognitive impairment (SCI) and patients with Alzheimer's disease (AD). In addition, significant $p$ values between the groups are shown

\begin{tabular}{|c|c|c|c|}
\hline & $\mathrm{HC}(\mathrm{SD} ;$ range $)(n=27)$ & $\mathrm{SCl}(\mathrm{SD}$; range) $(n=18)$ & $\mathrm{AD}(\mathrm{SD} ;$ range $)(n=28)$ \\
\hline Age (years) & $68.9(8.1 ; 52-80)$ & $66.5(11.2 ; 49-85)$ & $71.2(8.4 ; 54-86)$ \\
\hline Male/female & $16 / 11$ & $13 / 5$ & $18 / 10$ \\
\hline Education (median) & $3.3(3)$ & $3.5(3)$ & $4.0(4)$ \\
\hline GDS & - & $3.3(2.6 ; 0-7)$ & $3.3(2.6 ; 0-9)$ \\
\hline MMSE score & $29.0(1.1 ; 26-30)$ & $28.3(1.6 ; 25-30)$ & $22.4(2.0 ; 18-26)^{\mathrm{b}, \mathrm{d}}$ \\
\hline CAMCOG & - & $92.7(5.0 ; 86-100)$ & $74.5(8.4 ; 50-87)^{d}$ \\
\hline WMS & - & $121.12(15.2 ; 97-143)$ & $91.1(9.7 ; 74-103)^{d}$ \\
\hline Digit span forwards & $5.8(0.9 ; 5-7)$ & $4.8(0.8 ; 4-6)$ & $5.2(1.3 ; 3-8)$ \\
\hline Digit span backwards & $5.2(1.0 ; 3-7)$ & $3.8(1.1 ; 2-5)^{a}$ & $3.6(0.9 ; 2-5)^{b}$ \\
\hline TMT part A & $35.0(6.3 ; 28-46)$ & $44.5(15.9 ; 25-77)^{\mathrm{a}}$ & $85.3(80.4 ; 32-300)^{a, c}$ \\
\hline TMT part B & $79.3(25.9 ; 51-131)$ & $100.5(53.0 ; 44-208)$ & $226.7(90.4 ; 79-300)^{\mathrm{b}, \mathrm{d}}$ \\
\hline STROOP card 3 & $107.9(31.6 ; 72-160)$ & $132.3(60.4 ; 83-300)$ & $182.9(70.2 ; 100-300)^{a}$ \\
\hline $\begin{array}{l}{ }^{\mathrm{a}} p<0.05 \text { and } \\
{ }^{\mathrm{b}} p<0.001: \mathrm{HC} \text { versus } \mathrm{S} \\
{ }^{\mathrm{c}} p<0.05 \text { and } \\
\mathrm{d}_{p}<0.001: \mathrm{SCl} \text { versus } \\
\text { CAMCOG, Cambridge } \\
\text { Making Test; WMS, } \\
\text { neuropsychological te }\end{array}$ & $\begin{array}{l}\text { ramination; GDS, Geriatri } \\
\text { lemory Scale. TMT par } \\
\text { in points. }\end{array}$ & $\begin{array}{l}\text { on Scale; MMSE, Mini M } \\
B \text { and STROOP card }\end{array}$ & $\begin{array}{l}\text { Examination; TMT, Trail } \\
\text { en in seconds; other }\end{array}$ \\
\hline
\end{tabular}


and gender, $p<0.001)$. No AD-like changes, e.g. increased cortical phase shifts, were found in subjects with $\mathrm{SCl}$ compared with HCs. Parcellation into frontal, parietal and temporoparietal subregions did not yield different conclusions.

Table 2 shows the results of the linear regression analysis examining the association between the cortical phase shift of the whole brain (including all ROIs) and the scores of neuropsychological testing corrected for age and gender in subjects with $\mathrm{SCl}$. A significant association was found between memory function (WMS) and the cortical phase shift $(\beta=-0.544, p=0.007)$. No significant association was found between other cognitive functions and the cortical phase shift. Parcellation into frontal, parietal and temporoparietal subregions showed a highly significant association between the cortical phase shift in the frontal region in subjects with $\mathrm{SCl}$ and memory function (WMS) $(\beta=-0.721$, $p<0.0001$ ), and a less significant association with global cognitive functioning (MMSE) $(\beta=-0.519, p=0.021)$. Within the parietal region, a less significant association was also found with memory function (WMS) $(\beta=-0.406, p=0.041)$. It should be noted that these results were not corrected for multiple comparisons and therefore should be interpreted with care, especially those with moderate significance (i.e. 0.05-0.01).
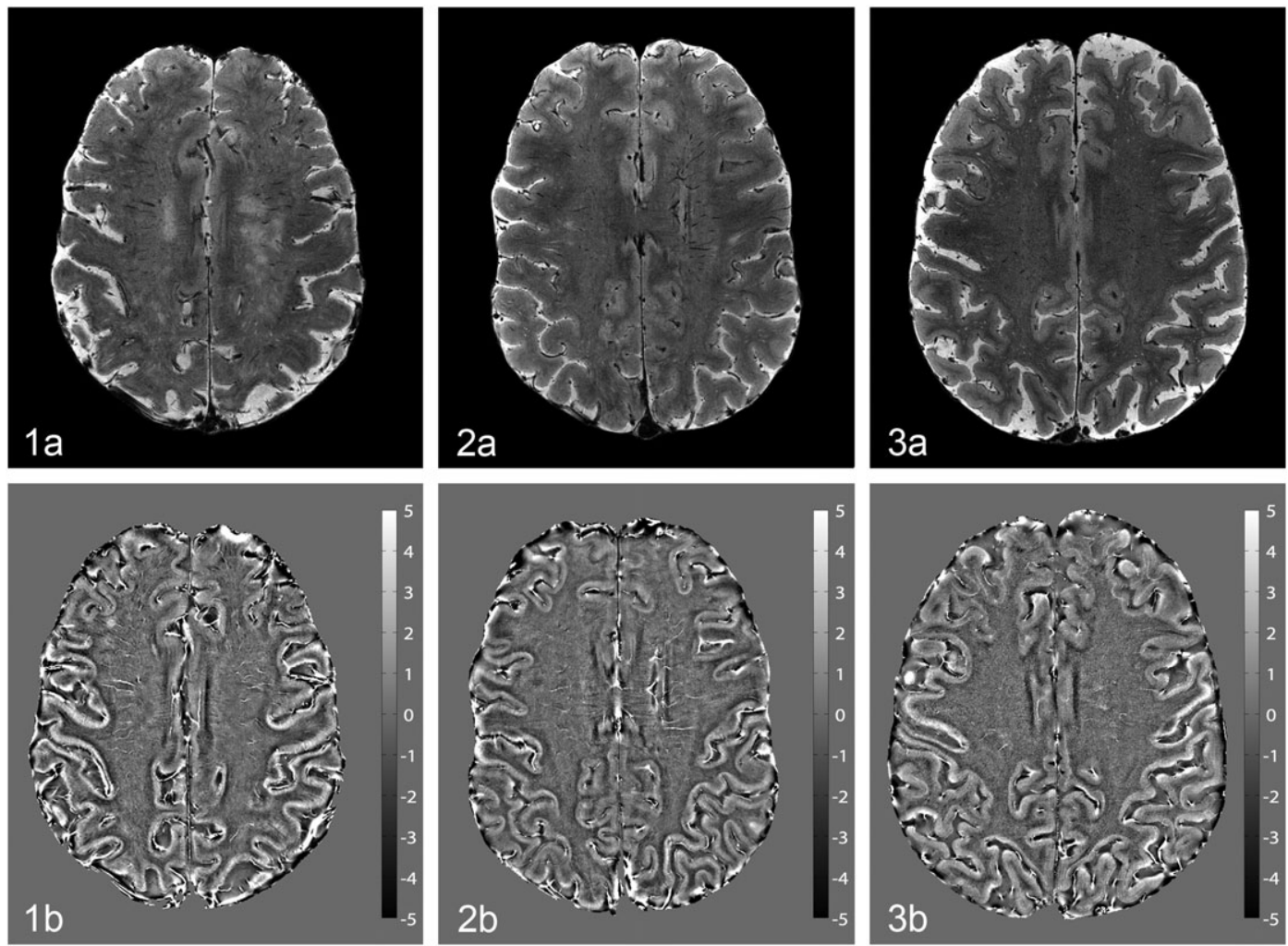

Figure 1. Representative magnitude (a) and phase (including a scale bar in hertz) (b) images acquired from a patient with Alzheimer's disease (1), a subject with subjective cognitive impairment (2) and a healthy control (3).

Table 2. $\beta$ and $p$ values correlating cortical phase shift with the scores of neuropsychological testing in subjects with subjective cognitive impairment, adjusted for age and gender

\begin{tabular}{|c|c|c|c|c|c|}
\hline Cognitive domain & Cognitive test & & & & \\
\hline & & $\beta$ & Std. error $B$ & Partial $r$ & $P$ value \\
\hline Depression & GDS & -0.007 & 0.014 & -0.009 & 0.991 \\
\hline Global cognitive functioning & MMSE & -0.238 & 0.011 & -0.278 & 0.297 \\
\hline Global cognitive functioning & CAMCOG & -0.251 & 0.004 & -0.300 & 0.320 \\
\hline Memory & WMS & -0.544 & 0.001 & -0.667 & $0.007^{*}$ \\
\hline Psychomotor speed & TMT part A & 0.616 & 0.002 & 0.445 & 0.096 \\
\hline Executive function (cognitive flexibility) & TMT part B & 0.250 & 0.001 & 0.171 & 0.541 \\
\hline Executive function (inhibition) & STROOP card 3 & -0.060 & 0.000 & -0.068 & 0.863 \\
\hline
\end{tabular}

CAMCOG, Cambridge Cognitive Examination; GDS, Geriatric Depression Scale; MMSE, Mini Mental State Examination; TMT, Trail Making Test; WMS, Wechsler Memory Scale. 


\section{DISCUSSION}

The major finding of this study is that, in subjects with $\mathrm{SCl}$, an increased cortical phase shift measured with high-field MRI is associated with a poorer memory performance, although, as a group, subjects with $\mathrm{SCl}$ did not show an increased phase shift compared with HCs. The finding of an increased cortical phase shift being related to memory performance is important new information, as it is still unclear whether $\mathrm{SCl}$ represents a first stage of $A D$ or a sign of pre-clinical $A D$, and results from previous studies are inconclusive with regard to the rate of decline and risk for conversion to AD dementia (1). Previous longitudinal and epidemiological studies have suggested that $\mathrm{SCl}$ is a precursor of $A D$ $(3,37,38)$, and therefore we hypothesized that we might find an increased phase shift, related to AD pathology, in subjects with $\mathrm{SCl}$ compared with controls, but that this phase shift would be lower relative to that of patients with AD. However, we did not find an increased cortical phase shift in subjects with $\mathrm{SCl}$ compared with HCs. Our findings might be explained by studies demonstrating that the majority of subjects with $\mathrm{SCl}$ do not develop $A D$, as there is only a $20 \%$ chance that $S C l$ will progress to dementia in this group (39), and multiple factors contribute to the presence of cognitive complaints, such as depression, anxiety and quality of life (11-13). Moreover, $\mathrm{SCl}$ is a heterogeneous group in which some pre-AD subjects might show an increase in phase, whereas non-AD cognitive impairment is associated with a phase decrease, perhaps suggesting a different mechanism for this group.

Our study shows that the cortical phase shift, determined on $T_{2}{ }^{*}$-weighted MRI at 7T, is associated with memory performance in subjects with $\mathrm{SCl}$. In contrast, global cognition, executive function and psychomotor speed are not associated with the cortical phase shift in these subjects. Based on previous studies, we expected to find an association between the iron-sensitive phase shift and cognition (40). However, assuming that the cortical phase shift is an indirect marker of the amount of amyloid plaques, the association would be more complicated. Previous studies have shown that this association is not straightforward and is most probably influenced by the presence of NFTs, as discussed in a review by Nelson et al. (22). The dynamic biomarkers model of $A D$ states that $A D$ starts with an increase in $A \beta$ in the brain, followed by the formation of NFTs and, at a later stage, memory is impaired when the amount of $A \beta$ is still increasing (41). As we found an association between the cortical phase shift and memory, and no other cognitive domain, this implies that, in subjects with $\mathrm{SCl}$, the cortical phase shift might be a marker to demonstrate very early changes in the brain related to memory function.

Our data demonstrate that subjects with SCI do not show ADlike phase changes in comparison with $\mathrm{HCs}$. Although the $\mathrm{SCl}$ group performs slightly lower on the cognitive tests than the $\mathrm{HC}$ group, our results also show no highly significant differences in cognitive function between the groups. Several explanations for these findings are possible and are partly described above. If $\mathrm{SCl}$ is indeed an early $\mathrm{AD}$ stage, in which AD pathology is present without the presence of cognitive symptoms, as suggested by several studies, our data indicate that phase changes would only appear at a later stage of the disease when AD pathology is more severe and starts to have an effect on brain function. Another explanation for our results might be that $\mathrm{SCl}$ is not strongly associated with $A D$, as it is related to many factors other than $A D$, and only a small subset of the subjects with $\mathrm{SCl}$ develop $\mathrm{AD}$
$(10-13,42)$. Alternatively, because phase changes are measured at a group level, it might be that, as most subjects with $\mathrm{SCl}$ do not develop $A D$, the differences between controls and subjects with $\mathrm{SCl}$ are too small to be significant. The investigation of cortical phase changes in longitudinal studies in subjects with $\mathrm{SCl}, \mathrm{MCl}$ and $\mathrm{AD}$ to evaluate the possibility of detecting early $A D$ pathology over time could provide more insight into $\mathrm{SCl}$ and the development of AD pathology, and the association with cortical phase changes and cognitive performance.

One overall limitation of this study is that phase measurements may partly be influenced by the geometry and orientation of the individual structures (21). To limit these effects as much as possible, all participants were positioned in the same manner and, for every subject, the phase measurements were performed in the same way and were averaged to cancel out the possible effects of geometry and orientation. Although it is most likely that the difference in phase shift between groups is mainly attributable to iron, other compounds may contribute to a change in phase shift, such as deoxyhemoglobin, myelin and proteins $(36,43)$.

In conclusion, in this study, we have shown that patients with $A D$ demonstrate an increased cortical phase shift, indicating greater iron accumulation, compared with HCs. Moreover, these cortical phase shifts are associated with decreased memory performance in subjects with $\mathrm{SCl}$. Although previous studies have suggested that, in $\mathrm{SCl}, \mathrm{AD}$-like changes may occur before cognitive decline becomes manifest, our data do not show any signs of AD-like high-field $T_{2}{ }^{*}$-weighted cortical phase shifts at a group level in subjects with $\mathrm{SCl}$.

\section{Acknowledgements}

This research was performed within the framework of CTMM, the Center for Translational Molecular Medicine (www.ctmm.nl), project LeARN (grant $02 \mathrm{~N}-101$ ). The authors thank Mrs G. Labadie for her help in recruiting, interviewing and planning all the participants.

\section{REFERENCES}

1. Jessen $F$, Amariglio RE, van Boxtel M, Breteler M, Ceccaldi M, Chetelat G, Dubois B, Dufouil C, Ellis KA, van der Flier WM, Glodzik L, van Harten AC, de Leon MJ, McHugh P, Mielke MM, Molinuevo JL, Mosconi L, Osorio RS, Perrotin A, Petersen RC, Rabin LA, Rami L, Reisberg B, Rentz DM, Sachdev PS, de la Sayette V, Saykin AJ, Scheltens $P$, Shulman MB, Slavin MJ, Sperling RA, Stewart $R$, Uspenskaya O, Vellas B, Visser PJ, Wagner M. A conceptual framework for research on subjective cognitive decline in preclinical Alzheimer's disease. Alzheimers Dement. 2014; 10: 844-852.

2. Dik MG, Jonker C, Comijs HC, Bouter LM, Twisk JW, Van Kamp GJ, Deeg DJ. Memory complaints and APOE-epsilon4 accelerate cognitive decline in cognitively normal elderly. Neurology 2001; 57: 2217-2222.

3. Jessen F, Wiese B, Bachmann C, Eifflaender-Gorfer S, Haller F, Kolsch $H$, Luck T, Mosch E, van den Bussche H, Wagner M, Wollny A, Zimmermann T, Pentzek M, Riedel-Heller SG, Romberg HP, Weyerer S, Kaduszkiewicz H, Maier W, Bickel H. Prediction of dementia by subjective memory impairment: effects of severity and temporal association with cognitive impairment. Arch. Gen. Psychiatry 2010; 67: 414-422.

4. van der Flier WM, van Buchem MA, Weverling-Rijnsburger AW, Mutsaers ER, Bollen EL, Admiraal-Behloul F, Westendorp RG, Middelkoop HA. Memory complaints in patients with normal cognition are associated with smaller hippocampal volumes. J. Neurol. 2004; 251: 671-675

5. Striepens N, Scheef L, Wind A, Popp J, Spottke A, Cooper-Mahkorn D, Suliman $\mathrm{H}$, Wagner $\mathrm{M}$, Schild $\mathrm{HH}$, Jessen F. Volume loss of the medial temporal lobe structures in subjective memory impairment. Dement. Geriatr. Cogn. Disord. 2010; 29: 75-81. 
6. Saykin AJ, Wishart HA, Rabin LA, Santulli RB, Flashman LA, West JD, McHugh TL, Mamourian AC. Older adults with cognitive complaints show brain atrophy similar to that of amnestic $\mathrm{MCl}$. Neurology 2006; 67: 834-842.

7. Stewart R, Godin O, Crivello F, Maillard P, Mazoyer B, Tzourio C, Dufouil C. Longitudinal neuroimaging correlates of subjective memory impairment: 4-year prospective community study. Br. J. Psychiatry $2011 ; 198: 199-205$.

8. Jessen F, Feyen L, Freymann K, Tepest R, Maier W, Heun R, Schild HH, Scheef $L$. Volume reduction of the entorhinal cortex in subjective memory impairment. Neurobiol. Aging 2006; 27: 1751-1756.

9. Stewart R, Dufouil C, Godin O, Ritchie K, Maillard P, Delcroix N, Crivello F, Mazoyer B, Tzourio C. Neuroimaging correlates of subjective memory deficits in a community population. Neurology 2008; 70: $1601-1607$

10. Eramudugolla R, Cherbuin N, Easteal S, Jorm AF, Anstey KJ. Self-reported cognitive decline on the informant questionnaire on cognitive decline in the elderly is associated with dementia, instrumental activities of daily living and depression but not longitudinal cognitive change. Dement. Geriatr. Cogn. Disord. 2012; 34: 282-291.

11. Montejo P, Montenegro M, Fernandez MA, Maestu F. Subjective memory complaints in the elderly: prevalence and influence of temporal orientation, depression and quality of life in a population-based study in the city of Madrid. Aging Ment. Health 2011; 15: 85-96.

12. Jorm $A F$, Christensen $H$, Korten $A E$, Jacomb PA, Henderson AS. Memory complaints as a precursor of memory impairment in older people: a longitudinal analysis over 7-8 years. Psychol. Med. 2001; 31: 441-449.

13. Knopman DS. Subjective cognitive impairment: fickle but fateful. Neurology 2012; 79: 1308-1309.

14. van Rooden S, Versluis MJ, Liem MK, Milles J, Maier AB, Oleksik AM, Webb AG, van Buchem MA, van der Grond J. Cortical phase changes in Alzheimer's disease at 7T MRI: a novel imaging marker. Alzheimers Dement. 2014; 10: e19-26.

15. Nakada T, Matsuzawa H, Igarashi $H$, Fujii $Y$, Kwee IL. In vivo visualization of senile-plaque-like pathology in Alzheimer's disease patients by MR microscopy on a 7 T system. J. Neuroimaging 2008; 18: 125-129.

16. Duce JA, Tsatsanis A, Cater MA, James SA, Robb E, Wikhe K, Leong SL, Perez K, Johanssen T, Greenough MA, Cho HH, Galatis D, Moir RD, Masters CL, McLean C, Tanzi RE, Cappai R, Barnham KJ, Ciccotosto GD, Rogers JT, Bush Al. Iron-export ferroxidase activity of betaamyloid precursor protein is inhibited by zinc in Alzheimer's disease. Cell 2010; 142: 857-867.

17. Lei $P$, Ayton S, Finkelstein DI, Spoerri L, Ciccotosto GD, Wright DK, Wong BX, Adlard PA, Cherny RA, Lam LQ, Roberts BR, Volitakis I, Egan GF, McLean CA, Cappai R, Duce JA, Bush Al. Tau deficiency induces parkinsonism with dementia by impairing APP-mediated iron export. Nat. Med. 2012; 18: 291-295.

18. Smith MA, Harris PL, Sayre LM, Perry G. Iron accumulation in Alzheimer disease is a source of redox-generated free radicals. Proc. Natl. Acad. Sci. U. S. A. 1997; 94: 9866-9868.

19. van Rooden $S$, Maat-Schieman ML, Nabuurs RJ, van der Weerd L, van Duijn S, van Duinen SG, Natte R, van Buchem MA, van der Grond J. Cerebral amyloidosis: postmortem detection with human 7.0-T MR imaging system. Radiology 2009; 253: 788-796.

20. Duyn JH. The future of ultra-high field MRI and fMRI for study of the human brain. Neuroimage 2012; 62: 1241-1248.

21. Yao B, Li TQ, van Gelderen P, Shmueli K, de Zwart JA, Duyn JH. Susceptibility contrast in high field MRI of human brain as a function of tissue iron content. Neuroimage 2009; 44: 1259-1266.

22. Nelson PT, Braak H, Markesbery WR. Neuropathology and cognitive impairment in Alzheimer disease: a complex but coherent relationship. J. Neuropathol. Exp. Neurol. 2009; 68: 1-14.
23. Jorm AF, Masaki KH, Davis DG, Hardman J, Nelson J, Markesbery WR, Petrovitch H, Ross GW, White LR. Memory complaints in nondemented men predict future pathologic diagnosis of Alzheimer disease. Neurology 2004; 63: 1960-1961.

24. Barnes LL, Schneider JA, Boyle PA, Bienias JL, Bennett DA. Memory complaints are related to Alzheimer disease pathology in older persons. Neurology 2006; 67: 1581-1585.

25. Lynoe N, Sandlund M, Dahlqvist G, Jacobsson L. Informed consent: study of quality of information given to participants in a clinical trial. BMJ 1991; 303: 610-613.

26. Folstein MF, Folstein SE, McHugh PR. "Mini-mental state". A practical method for grading the cognitive state of patients for the clinician. J. Psychiatr. Res. 1975; 12: 189-198.

27. Derix MM, Hofstede AB, Teunisse S, Hijdra A, Walstra GJ, Weinstein HC, van Gool WA. CAMDEX-N: the Dutch version of the Cambridge Examination for Mental Disorders of the Elderly with automatic data processing. Tijdschr. Gerontol. Geriatr. 1991; 22: 143-150.

28. Wechsler DA. A standardized memory scale for clinical use. J. Psychol. 1945; 19: 87-95.

29. Reitan RM. Validity of the Trail Making Test as an indication of organic brain damage. Percept. Mot. Skills 1958; 8: 271-276.

30. Stroop JR. Studies of interference in serial verbal reactions. J. Exp. Psychol. 1935; 18: 643-662.

31. Sheikh JA, Yesavage JA. Clinical Gerontology: A Guide to Assessment and Intervention. Howarth Press: New York; 1986.

32. McKhann G, Drachman D, Folstein M, Katzman R, Price D, Stadlan EM. Clinical diagnosis of Alzheimer's disease: report of the NINCDSADRDA Work Group under the auspices of Department of Health and Human Services Task Force on Alzheimer's Disease. Neurology 1984; 34: 939-944.

33. Schoenmaker M, de Craen AJ, de Meijer PH, Beekman M, Blauw GJ, Slagboom PE, Westendorp RG. Evidence of genetic enrichment for exceptional survival using a family approach: the Leiden Longevity Study. Eur. J. Hum. Genet. 2006; 14: 79-84.

34. Schar M, Kozerke S, Fischer SE, Boesiger P. Cardiac SSFP imaging at 3 Tesla. Magn. Reson. Med. 2004; 51: 799-806.

35. Haacke EM, Xu Y, Cheng YC, Reichenbach JR. Susceptibility weighted imaging (SWI). Magn. Reson. Med. 2004; 52: 612-618.

36. Duyn JH, van Gelderen P, Li TQ, de Zwart JA, Koretsky AP, Fukunaga M. High-field MRI of brain cortical substructure based on signal phase. Proc. Natl. Acad. Sci. U. S. A. 2007; 104: 11 796-11 801

37. Jonker C, Geerlings Ml, Schmand B. Are memory complaints predictive for dementia? A review of clinical and population-based studies. Int. J. Geriatr. Psychiatry 2000; 15: 983-991.

38. Reisberg B, Shulman MB, Torossian C, Leng L, Zhu W. Outcome over seven years of healthy adults with and without subjective cognitive impairment. Alzheimers Dement. 2010; 6: 11-24.

39. Mitchell AJ. The clinical significance of subjective memory complaints in the diagnosis of mild cognitive impairment and dementia: a meta-analysis. Int. J. Geriatr. Psychiatry 2008; 23: 1191-1202.

40. Schroder N, Figueiredo LS, de Lima MN. Role of brain iron accumulation in cognitive dysfunction: evidence from animal models and human studies. J. Alzheimers Dis. 2013; 34: 797-812.

41. Jack CR, Jr, Knopman DS, Jagust WJ, Shaw LM, Aisen PS, Weiner MW, Petersen RC, Trojanowski JQ. Hypothetical model of dynamic biomarkers of the Alzheimer's pathological cascade. Lancet Neurol. 2010; 9: 119-128.

42. Mitchell AJ. Is it time to separate subjective cognitive complaints from the diagnosis of mild cognitive impairment? Age Ageing 2008; 37: 497-499.

43. Duyn JH. Study of brain anatomy with high-field MRI: recent progress. Magn. Reson. Imaging 2010; 28: 1210-1215. 